\title{
The current status of sports participation among children with physical disabilities: mothers' expectations and anxieties regarding participation
}

\author{
Shibahara Miyuki ${ }^{1}$, Mitsuyo Makita $^{2}$, Hiroko Makita $^{3}$ \\ ${ }^{1}$ Kyorin University, ${ }^{2}$ Tokyo University of Technology, ${ }^{3}$ Toyohashi SOZO University
}

\begin{abstract}
This study, conducted in March 2012, involved a questionnaire survey of parents of children with physical disabilities. The self-reported questionnaire contained 30 items on the types of schools the children attended, as well as the children's ambulatory ability, frequency of participation in physical education classes, and status of participation in sports activities other than physical education classes. A total of 90 valid survey responses were obtained. The participation rate in physical education classes exceeded $88 \%$ in all schools, and included students who were restricted in the types of sports they could play. Many of the children who attended general public schools participated in sports activities other than physical education classes, while many of those who attended special schools had no experience of participating in such activities. We analyzed the data on 78 mothers with the phenomenological approach, and were able to classify their feelings about sports participation into the following 3 exhaustive descriptions: "a sense of alienation," "the presence of expectations for the child's growth," and "concern over negative impact brought on by new challenges." The results suggest the need to provide support for sports participation among older children, and to build a support system that can prevent mothers from developing a sense of alienation.
\end{abstract}

Keywords: Children with physical disabilities, physical education/sports classes, mothers' feelings, phenomenological approach

\section{Purpose}

As the popularity of the Paralympic Games has grown to include participants and spectators from across the globe, so has general public awareness of the ability of individuals with physical disabilities to participate in various sports. Along with basic lifestyle habits (e.g., sleeping, eating, and lifestyle patterns), sports activities have attracted attention for their effects on health. Widely perceived as a way of maintaining health and quality of life (QOL), a host of sports activities have been adopted by people of all ages - from school-age children to older adults - into their daily lives. Although playing sports is also known to positively contribute to the QOL and maintenance of health in children with physical disabilities, few studies have reported on the sports activities of these children ${ }^{1,2,3,4,5)}$. Furthermore, detailed investigations on this topic have yet to be conducted. Therefore, this study aimed to (1) investigate the status of participation of children with physical disabilities in physical education classes and other sports activities, as well as the types of sports in which the children were interested, and (2) identify how mothers view the participation of their children in sports activities. This study also explored issues related to sports participation and identified support necessary for children with disabilities to participate in sports.

\section{Material and methods}

\subsection{Data collection procedures}

A questionnaire survey on sports activities was performed in March 2012 with the parents of children with disabilities aged under 18 years who were living in the Japanese prefectures of Kanagawa (Yokohama City), Aichi (Okazaki City), and Niigata (Niigata City). The details of the survey were first explained to 112 parents in meetings held in schools located in these three municipalities. These parents had been invited to participate in this study through by letters and e-mail . The questionnaires were then distributed, and responses were returned by post.

Comprising 30 items, the self-reported questionnaire asked parents what types of schools their

Received Date: 2014/01/08 
children attended (i.e., general public schools, self-contained classrooms, special schools), along with their child's grade in school, ambulatory ability, frequency of participation in physical education classes, and status of participation in sports activities other than physical education classes. In addition, parents were asked a number of free-response questions with regard to their children's participation in sports activities. These free-response questions addressed the following issues: (1) concerns over the participation of the child in sports, (2) things that the parents wanted with respect to the participation of the child in sports, and (3) any comments the parents wished to provide regarding the participation of the child in sports.

\subsection{Analysis of free-response questions}

The answers parents provided to the free-response questions were analyzed with the phenomenological approach. Their answers were first repeatedly read to enable an understanding of the entire context. Through data reduction, the meaning of the phenomenon under investigation was then identified, extracted, coded, and categorized. Discrepancies and similarities in the data were compared, and the parents' recognition of their children's participation in sports was confirmed. To ensure the credibility of the research results, the data were checked by the researchers involved in this study.

\subsection{Ethical considerations}

This study was conducted with the approval of the ethics committee of the Faculty of Health Sciences, Kyorin University, Tokyo.

\section{Results}

\subsection{Types of schools and participation in physical education classes and sports activities}

A total of 90 valid survey responses were obtained (60 from Aichi, 13 from Kanagawa, and 17 from Niigata). Thirty-four children attended general public schools; 11, self-contained classrooms; and 45, special schools. None of the high school students attended general public schools. There were 69 children who were diagnosed with cerebral palsy.

The modes of mobility employed by the children were further examined to ascertain their ambulatory ability. As shown in Table 1, an independent gait was most commonly observed in in children in all types of schools, followed by the use of an electric wheelchair. However, 14 children used multiple modes of mobility. Many of the children who attended general public schools were able to walk independently ( $\chi^{2}$ test, $p=0.0198$ ).

Eighty of the children usually participated in physical education classes. They included

Table 1. The number of students who used a particuler mode(s) of transpotaition in relation to school grade

\begin{tabular}{|c|c|c|c|c|c|}
\hline & & Ambulatory & Cane gait & $\begin{array}{l}\text { W/Ch } \\
\text { independence }\end{array}$ & $\begin{array}{l}\text { W/Ch } \\
\text { assistance }\end{array}$ \\
\hline \multirow{6}{*}{$\begin{array}{c}\text { Elementary } \\
\text { school }\end{array}$} & $1 \mathrm{st}$ & 5 & 2 & 0 & 0 \\
\hline & 2nd & 6 & 1 & 1 & 2 \\
\hline & 3rd & 4 & 5 & 4 & 2 \\
\hline & 4th & 5 & 0 & 3 & 0 \\
\hline & 5th & 3 & 1 & 1 & 1 \\
\hline & 6th & 7 & 3 & 2 & 0 \\
\hline \multirow{3}{*}{$\begin{array}{c}\text { Junior high } \\
\text { school }\end{array}$} & $1 \mathrm{st}$ & 2 & 4 & 5 & 3 \\
\hline & 2nd & 4 & 2 & 3 & 1 \\
\hline & $3 r d$ & 4 & 0 & 2 & 1 \\
\hline \multirow{3}{*}{$\begin{array}{l}\text { High- } \\
\text { school }\end{array}$} & $1 \mathrm{st}$ & 1 & 0 & 1 & 2 \\
\hline & 2nd & 3 & 1 & 3 & 1 \\
\hline & $3 r d$ & 0 & 1 & 3 & 1 \\
\hline
\end{tabular}

those who were restricted in the types of sports they could play. However, 9 of the children did not participate in physical education classes, and had medical reasons for skipping these. The participation rate exceeded $88 \%$ for all types of schools (Table 2 ).

\subsection{Status of sports participation}

In terms of sports activities other than physical education classes, 39 children were described as those who "currently participate;" 17, those who "had participated in the past;" and 33, those who "had never participated." 
Many of the children who attended general public schools participated in sports activities other than physical education classes, whereas many of those who attended special schools had no experience of participating in such activities $\left(\chi^{2}\right.$ test, $p=0.00087$ ) (see Table 3). No significant difference was observed in relation to grade and ambulatory ability. Of the 33 children who had never participated in sports activities other than physical education classes, 18 did not participate in such activities despite having opportunities to do so. The main reasons included: "Not interested in sports" (7 subjects), "concerns over the safety of the child" (7), "distance and transportation problems" (2), "scheduling problem" (1), "concerns over the cost burden" (1), and "other" (6).

Table 2.Number of participants in physical education classes

\begin{tabular}{ccc}
\hline & participation* & exemption \\
\hline general public school & $30(88.2 \%)$ & $4(11.8 \%)$ \\
\hline $\begin{array}{c}\text { self-contained } \\
\text { classroom }\end{array}$ & $11(100 \%)$ & 0 \\
\hline special school & $40(88.9 \%)$ & $5(11.1 \%)$ \\
\hline total & $81(90.0 \%)$ & $9(10.0 \%)$ \\
\hline
\end{tabular}

* including those who are restricted regarding the types of sports
Table 3.Experience participating in sports activities other than physical education classes.

\begin{tabular}{ccccr}
\hline & current & previous & none & total \\
\hline $\begin{array}{c}\text { general } \\
\text { public } \\
\text { school }\end{array}$ & 21 & 6 & 7 & 34 \\
\hline $\begin{array}{c}\text { self- } \\
\text { contained } \\
\text { classroom }\end{array}$ & 8 & 2 & 1 & 11 \\
\hline $\begin{array}{c}\text { special } \\
\text { school }\end{array}$ & 10 & 10 & 25 & 45 \\
\hline total & 39 & 18 & 33 & 90 \\
& & $X^{2}$ test & $p=0.00087$ &
\end{tabular}

Table4. The children's favorite sports/sports that they liked.

\begin{tabular}{|c|c|c|c|c|c|c|c|}
\hline \multicolumn{2}{|c|}{$\begin{array}{l}\text { Lower and middle } \\
\text { elementary school }\end{array}$} & \multicolumn{2}{|c|}{ Higher elementary school. } & \multicolumn{2}{|c|}{ Junior high school } & \multicolumn{2}{|c|}{ High-school } \\
\hline & No. & & No. & & No. & & No. \\
\hline swimming & 10 & Soccer & 7 & swimming & 5 & swimming & 2 \\
\hline Dodgeball & 6 & swimming & 5 & Boccia & 4 & Baseball & 2 \\
\hline Soccer & 5 & Baseball & 5 & Baseball & 3 & Soccer & 2 \\
\hline Track and field & 3 & Track and field & 4 & Basketball & 3 & ping-pong & 1 \\
\hline ping-pong & 2 & ping-pong & 2 & Soccer & 3 & Tennis & 1 \\
\hline Baseball & 2 & Basketball & 2 & Track and field & 2 & Boccia & 1 \\
\hline Tennis & 2 & Boccia & 2 & dance & 2 & & \\
\hline Boccia & 2 & Dodgeball & 1 & ping-pong & 1 & & \\
\hline dance & 2 & & & & & & \\
\hline Basketball & 1 & & & & & & \\
\hline
\end{tabular}

Table 4 presents the results on the children's favorite sports ("sports that children like to play"), according to their grades. No relationship was observed between ambulatory ability (e.g., ambulation vs. use of a wheelchair) and the children's favorite sports or the ones they were most interested in playing. The children liked and were interested in participating in these sports activities: swimming, soccer, and baseball. However, they were not interested in playing boccia and dodgeball, even though they liked these sports.

\subsection{The mothers' feelings}

Of the 90 parents who responded to the survey, 87 answered the free-response questions, who consisted of 78 mothers, 5 fathers, and 4 non-parents (e.g. grandparents and sisters). The data obtained on the 78 mothers were analyzed using the phenomenological approach. As shown in Table 5, data were classified into the following 3 exhaustive descriptions: "a sense of alienation," "the presence of expectations for the child's growth," and "concerns over negative impact brought on by new challenges." These were further categorized into several theme clusters.

For instance, "sense of alienation" comprised the themes, "parents are the only people who understand the child" and "dissatisfaction with society." The first theme ("parents are the only people 
who understand the child") also included the secondary theme, "the child has a low level of competence as perceived by the parents," while "dissatisfaction with society" included dissatisfaction with "environmental barriers" that consisted of a lack of sports facilities, trainers, and information.

"Expectations for the child's growth" comprised the themes, "spirituality," "physical strength," and "advanced health," which were considered to be achieved through participation in sports activities. These three themes ("spirituality," "physical strength," and "advanced health") were further conceptualized or defined as "improved sociality," "confidence/continuity," and "building up of physical strength," respectively.

"Concerns over negative impact brought on by new challenges" comprised the following cluster of themes: "increased care burden," "anxiety about developing other disabilities," and "possibility of bothering other people," which were further explained by "anxiety over the child's competence," "anxiety over safety," and "anxiety over whether the child is accepted as a friend," respectively.

Table 5 .Analysis of mothers' feelings based on the phenomenological approach.

\begin{tabular}{|c|c|c|}
\hline $\begin{array}{l}\text { Exhaustive } \\
\text { Description }\end{array}$ & Clusters of Themes & Formulated Meanings \\
\hline \multirow{2}{*}{ sens of alination } & $\begin{array}{l}\text { parents are the only people who understand } \\
\text { the child }\end{array}$ & $\begin{array}{l}\text { low level of child's competence perceivd by } \\
\text { the parents }\end{array}$ \\
\hline & dissatisfaction with society & $\begin{array}{l}\text { enviromental barriers (lack of sports } \\
\text { facilities,sports triners, information) }\end{array}$ \\
\hline \multirow{3}{*}{$\begin{array}{l}\text { expectations for } \\
\text { child's grouth }\end{array}$} & spirituality & improved sociality \\
\hline & physical strenghth & confidence/continuity \\
\hline & advanced health & $\begin{array}{l}\text { building up physical strenghth } \\
\text { whether child can show interest }\end{array}$ \\
\hline \multirow{3}{*}{$\begin{array}{l}\text { nagative impacts } \\
\text { brought about by } \\
\text { having new } \\
\text { challenges }\end{array}$} & increased care burden & anxiety over the child's competence \\
\hline & anxiety about developing other disabilities & anxiety over safety \\
\hline & possibility of bothering other people & $\begin{array}{l}\text { anxiety over whether the child is accepted as } \\
\text { a friend }\end{array}$ \\
\hline
\end{tabular}

\section{Discussion}

More than $80 \%$ of the children participated in physical education classes, and most were actually engaged in sports activities during these classes. However, some of the parents thought that "independent activity," often implemented in self-contained classrooms and special schools, involved a general "gymnastics class" as it provided training similar to functional training/exercises. In both independent activity and physical education classes, teachers usually provided students lessons on a one-on-one basis. Irrespective of whether independent activity or physical education classes were conducted, the high rate of participation suggests that each school gave thoughtful consideration to each student's disability status in conducting these lessons.

Children who were currently participating in or had participated in sports activities in local after-school sports clubs were most frequently found in general public schools, likely due to the fact that children who attend special schools tend to have more severe disabilities and are often less encouraged to engage in sports. Moreover, the results showed a relatively high rate of participation in sports among early elementary school children, but a decreased frequency in independent walking among older children. This suggested that support for their participation in sports activities decreased as they got older.

The lack of support for participation in sports among older children is also a major issue. In compulsory education, almost all children with physical disabilities participate in physical education classes and independent activities in school, and many of them are engaged in local sports activities. By the time they graduate from middle/high school, however, their frequency of participation in physical education classes decreases, and they rarely engage in sports. Furthermore, older children with physical disabilities frequently require a larger amount of care than do younger children. The care burden borne by their parents also increases. Thus, it is crucial that we strive to prevent these children 
and their parents from developing a sense of alienation.

Although the children whose parents we surveyed in our study liked boccia as a sport (often adopted in physical education classes in school), they were not interested in playing it. Boccia was designed to be played by children with cerebral palsy, and children without disabilities do not typically play it. The particularity of this sport may have contributed to our abovementioned findings on the sport's popularity with the children. Irrespective of ambulatory ability and age, football, swimming, and baseball were among their most favorite sports to participate in and were also among those most interesting to the children. These sports were taught to have aroused great interest in the children due to the great deal of media attention that has been focused on these sports in particular. However, the results also showed that the number of sports the children liked and were interested in playing decreased as they reached high school age. The reason for this loss of interest in playing sports needs to be investigated further in order to encourage sports participation and identify factors affecting support for participation in older children

"A sense of alienation," "the presence of expectations for the child's growth," and "concerns over negative impact brought on by new challenges" were extracted as primary themes describing mothers' feelings regarding their children's sports participation. As shown in Fig. 1, an analysis of the relationships among these categories indicated that mothers' expectations for the child's growth through sports activities were suppressed through "a sense of alienation" and "concerns over negative impact brought on by new challenges." Therefore, we concluded that children's participation in sports can be facilitated by reducing mothers' "sense of alienation" and "concerns over negative impact brought on by new challenges" and increasing their "expectations for the child's growth."
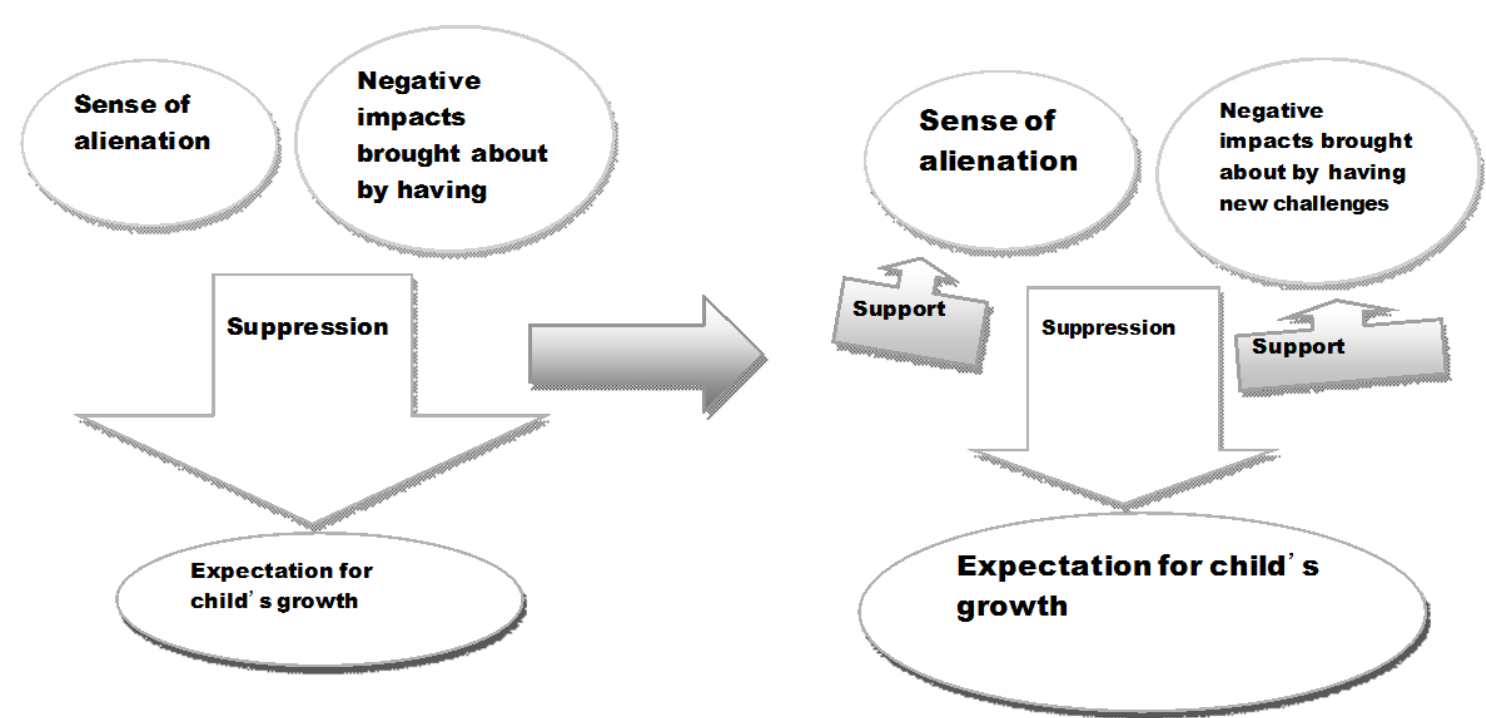

Fig1.Diagram showing the relationship between mothers' feelings and encouragement for children to participate in sports

Factors leading to the mothers' "sense of alienation" were disorganized services and environments for people with disabilities. Inoue ${ }^{6)}$ also stated that parents had a desire for their children to participate in local sports and recreational activities after high school graduation as part of their social lives; however, in actuality, children rarely participate in sports, except during school activities. Primary reasons given for non-participation were the lack of knowledge on the part of the children and parents about the benefits and effects of participating in sports, as well as insufficient information on disability sports and opportunities to experience them. These reasons reveal the need to: establish a place for sporting activity in the lives and environments of children with disabilities, provide an opportunity for them to participate, and make information on playing sports readily available to parents, caregivers, and educators. There is also the necessity for maintaining services and environments for individuals with disabilities in which their health and quality of life may be nurtured and further improved ${ }^{7}$.

Such barriers to social participation among children with disabilities are also the main factors contributing to the development of a sense of alienation in mothers. The results also showed that the 
mothers underestimated their children's abilities, and strongly considered themselves to be the only people who understood their children. This suggests inadequacies in social support and services for children with disabilities. Mothers often have fewer opportunities to take time out from the care of their children and to objectively assess their children's abilities. Consequently, the mothers in our study appeared to perceive their children primarily as objects requiring their care. This may have contributed to mothers' underestimations of their children's abilities, which suggests the need to avoid leaving all care responsibilities to mothers and to expand their networks of social support.

Mothers who were concerned over "the negative impact brought on by new challenges" were sometimes worried about the safety of their children in sports activities because these mothers feared that their children, whom they perceived as having lower levels of physical competence, might develop additional disabilities and require further care. Thus, the parents had 2 major concerns about their children participating in sports: (1) the presence of support, which is required when their children participate in sports activities; and (2) additional care, which may be needed if the children develop additional disabilities through sports. These concerns are taught to emerge from the mothers' complaints and anxieties about the care they are frequently relied upon to provide. These concerns can also contribute to the development of a sense of alienation in these mothers. On the other hand, the mothers also had "expectations for the child's growth" through participation in sports activities. Kojima ${ }^{8)}$ reported that even physically disabled children can be involved in sports, by devising appropriate methods of instructions for them and developing clearer guidelines for trainers, educators, as well as caregivers. In reality, however, a number of problems exist with regard to increasing sports participation, as discussed earlier.

Sporting and recreational activities are reportedly effective in improving social participation and physical functioning in children with disabilities. There is the need for attending pediatricians to provide parents with appropriate suggestions regarding their children's participation in sports activities. ${ }^{9)}$ Applying information technology (IT) to researching and determining the optimal amounts of physical activity for children with disabilities could perhaps constitute an initiative to that end, as might establishing community-based programs for social participation ${ }^{10)}$. One of the most important challenges for pediatric rehabilitation and healthcare professionals is finding ways to increase physical activity and fitness among youth with disabilities in community-based settings. The use of information technology (IT) to customize physical activity programs for youth with disabilities offers a promising approach to addressing this important health issue in the future.

In conclusion, children's participation in sports may be facilitated by reducing mothers' "sense of alienation" and "concerns over negative impact brought on by new challenges," and increasing their "expectations for the child's growth" through sports. In future, providing mothers with multilateral support, such as by expanding their networks of social support, is crucial to preventing a sense of alienation from developing. It is also essential to secure the safety of sports for the disabled, establish appropriate methods and channels through which sports may be introduced, train and educate instructors, and make relevant information more readily accessible. To achieve these goals, we must strive to create a cooperative environment where people involved in the lives of children with disabilities can share relevant information with one another.

\section{References}

1) Okuda Kuniharu, Hguchi Yumi et al. A survey on awareness of the efficacy of sports for nurturing independent living among athletes with severe disabilities. J Rehabili Health Sci 2006;4:11-21. (Japanese)

2) Hayakawa Kimiyasu. Effectiveness of "Cognitive Movement Training" for Children with Mental Disabilities. Bulletin of Sendai University 2011;42:79-88.

3) Nagasima Yosihisa, Kimura Chiemi, Hujisawa Ysiko, Nakano Koyoko. Activation of life of severely disabled through life. Annual Report of Asahikawa-so 2009;40:18-25. (Japanese)

4) Maekawa Mirai, Araga Hirosi, Daihasi Satoko. Sports activities in residential care children with severe disabilities. Rehabilitation Sport 2010;29:27. (Japanese)

5) Van den Berg-Emons RJ, Van Baak MA, Speth L, Saris WH. Physical training of school children with spastic cerebral palsy: effects on daily activity, fat mass and fitness. Int J Rehabil Res 1998;21(2):179-194. 
6) Inoue Yuri, Kitayama Jun, Satouti Yasukazu et al. A survey of sports awareness among handicapped children: from questionnaires administered to parents with handicapped children on Awaji Island. Rehabilitation Research of Kobe International University 2010;1:91-96. (Japanese)

7) Muranaka Ami, Takenaka Kouji. A study on barriers preventing physical activity participation in children with physical disabilities. Sports Medicine Science Research, Japan Sports Association 2003 :255-259. (Japanese)

8) Kojima Masaharu. Attempting to introduce sports to children with severe disabilities: classroom practice reports on parent-child sports experiences during summer vacation. Bulletin of Rehabilitation Research 2004;43-46. (Japanese)

9) Fragala-Pinkham MA, O’Neil MA, Bjomson KF, Boyd RN. Fitness and physical activity in children and youth with disabilities. Int J Pediatr 2012

10) Rimmer JA, Rowland JL. Physical activity for youth with disabilities: a critical need in an underserved population. Dev Neurorehabil 2008;11(2):141-8. 
BIOPHILIA 2014-1

Original article (Research) 